\title{
EDITORIAL
}

\section{EL SISTEMA DE ARBITRAJE EN LA CIENCIA: COMPLEJO, CONTROVERTIDO PERO VIGENTE}

\author{
Prof. Dra. Sara Mendoza Parra
}

$\mathrm{C}^{1}$ siglo XX nos legó una ciencia gestionada a partir de tres procesos básicos: Cproducir conocimiento, opinar con expertez respecto de esa producción y tomar decisiones políticas al respecto (1). La ciencia, sus actividades y resultados, al igual que todo proceso social, necesita ser evaluada permanentemente y esto implica observar, por un lado, el comportamiento del sistema que certifica el conocimiento, es decir, el arbitraje mediante iguales o los pares y, por otro, el comportamiento de los indicadores que miden la producción científica. Sólo así los científicos podrán saber si su investigación es útil y de calidad, las entidades financiadoras podrán corroborar que los fondos destinados a la ciencia se han canalizado adecuadamente (2) y los gobiernos podrán garantizar ante la sociedad el correcto empleo de los recursos dispuestos para la ciencia (3).

El sistema de arbitraje (peer review), originado en el siglo XVIII, es el instrumento de canonización del conocimiento y eje fundamental para determinar aquel que es válido y de calidad (4). Los que actúan como revisores tienen la responsabilidad de salvaguardar no sólo la reputación de una revista, sino también el prestigio de los autores que publican sus trabajos en ellas (5). En concreto, el sistema opera para determinar qué investigación se financia o qué artículo, producto de una investigación, se publica.

Como es sabido, consiste en que dos o más revisores leen y analizan artículos o proyectos para determinar la validez e impacto de ideas y resultados en el mundo científico. El trabajo que se desarrolla es complejo, anónimo y no remunerado (6) cuyas principales funciones son (1): estandarizar la conducta investigadora y por ende controlar la calidad de la investigación; reforzar la conformidad ideológica entre los investigadores y determinar quién entra en la categoría de investigador; recompensar la investigación realizada, cuestión que influye en la dirección que deben seguir las futuras investigaciones, $y$ asumir la responsabilidad colectiva de los resultados de las investigaciones y maximizar su impacto. 
A pesar de estas bondades, el sistema de arbitraje no deja de tener problemas de diversa índole $(1,4,7)$, a saber:

- Dificultades en el reclutamiento de revisores prestigiosos por parte de los editores. Esto muchas veces se resuelve reemplazando a los expertos por investigadores con menor prestigio, más jóvenes, más inexpertos, que aceptan ser árbitros, sin tener experiencia en la tarea, para promocionar sus carreras.

- Por exceso de trabajo, un referí puede solicitar ayuda a un colega para que evalúe todo o parte del trabajo que le han encomendado. Ocurrido esto, los editores no siempre tienen conciencia que un trabajo puede tener información relevante para el trabajo de investigación propio y caer en manos de un desconocido que, experto o no, puede ser rival del autor del escrito.

- La lentitud del sistema, pues todo el proceso de revisión de un trabajo (entiéndase: distribución a los revisores, revisión propiamente tal y recuperación de los documentos definitivos) puede demorar, indebidamente, varios meses, según el rigor y orden que cada revista tenga implementado en este proceso editorial.

- Inconsistencia en los juicios de los revisores, pues cuando se ha analizado la fiabilidad del sistema de revisión, es decir la consistencia en los juicios emitidos por un revisor sobre un mismo artículo en ocasiones sucesivas, o en los juicios emitidos por diferentes revisores sobre un mismo original, se ha comprobado que los revisores, aun cuando pueden estar de acuerdo en la decisión que sugieren a la revista, esto es aceptar, sugerir modificaciones o rechazar un artículo, lo hacen por razones distintas, incluso muchas veces contradictorias.

- Publicación de artículos con problemas estadísticos serios, como por ejemplo, aceptar la supuesta normalidad en el comportamiento de las muestras de las poblaciones de estudio, cuando no lo son. El caso es que a partir de bastantes publicaciones que tienen estos errores, muchas veces publicadas en revistas de prestigio, se toman decisiones políticas respecto a la ciencia o sirven de punto de partida para investigaciones posteriores.

- Rechazar, por razones incorrectas, artículos que informan descubrimientos importantes o son innovadores y que posteriormente, publicados en otras revistas, han resultado ser muy influyentes en sus respectivas disciplinas y resultan ser obras muy citadas.

- Tendencia a publicar trabajos con resultados positivos. En muchos estudios se ha comprobado que la evaluación del grado de rigor metodológico es más rigurosa en artículos que exponen resultados positivos y la probabilidad de publicar aumenta cuando un trabajo presenta resultados estadísticamente significativos, en comparación con artículos que tengan resultados negativos. Así, los investigadores parecen tener conciencia de esto y desisten en enviar a una revista un artículo con estas características, invisibilizando resultados también muy importantes que podrían evitar seguir realizando y financiando estudios intrascendentes.

- Tendencia de revisores y editores a aceptar trabajos de autores más conocidos, 
el llamado efecto "halo". Lo anterior, porque el prestigio de los autores va acompañado de más citas a sus trabajos y por ende mayor impacto para las revistas que los publican.

- Sexismo y nepotismo como las formas de discriminación más difíciles de erradicar en el sistema de revisión por pares. Se basan en redes personales y prejuicios que actúan de sobremanera en contra de las mujeres y operan cuando el revisor está sesgado jerárquicamente hacia los pares mayores y mejor conectados, características que suelen tener mayoritariamente los hombres.

- Problemas éticos, por ejemplo, cuando un revisor valiéndose del anonimato, que por un lado resguarda que se juzgue el trabajo y no al autor, por otro permite que ese revisor puede decidir no financiar un proyecto o no publicar los resultados con el objeto de apropiarse de las ideas o técnicas para sus propios intereses de investigación. Otro ejemplo es apropiarse de la bibliografía para lograr más rápido un nivel de competencia comparable con el investigador que se está evaluando.

- Incapaz de detectar el fraude, el plagio y la publicación duplicada.

Con todo, frente al sistema de arbitraje, en la actualidad existe acuerdo en que no es un sistema perfecto, es subjetivo, parcial y conservador (5), pero es el mejor que se tiene (3) o el menos malo (4).

Propuestas de cambio son muchas, algunas radicales como eliminar completamente el sistema de arbitraje, a otras más de consenso que incluso ya están operando, tales como aplicar la revisión con doble ciego (ni autores ni revisores saben que están vinculados en la revisión de un artículo o proyecto).

Enfermería, siendo aún una ciencia muy nueva, debe considerar estas experiencias y entender que el sistema de arbitraje, aunque complejo y contradictorio, aún está vigente y que es un indicador de calidad de la ciencia, y los equipos que lideran los procesos editoriales en el área deben procurar incluir en este sistema a personas de incuestionable comportamiento ético, responsables, honradas, rigurosas y de reconocido prestigio, no sólo en las líneas de investigación que produce ciencia, sino también en la expertez por investigar y publicar.

Las revistas científicas de enfermería que se precien de buena calidad deben someter a evaluación permanente este sistema y procurar mejorarlo en beneficio del valor social que se necesita tener de la ciencia de enfermería.

\section{REFERENCIAS}

1. Pérez SE. Evaluación, transparencia y democracia. Revista CTC. 2007; 8(3): 173181. Hallado en: http://dialnet.unirioja.es/servlet/articulo? codigo $=2378588$. Acceso en 28 marzo 2011. 
2. Milanés GY, Pérez RY, Peralta GMJ, Ruiz RME. Los estudios de evaluación de la ciencia: aproximación teórico-métrica. Acimed. 2008; 18(6). Hallado en: http:// scielo.sld.cu/scielo.php?pid=S1024-94352008001200004\&script=sci_arttext. Acceso en 28 marzo 2011.

3. Pacheco-Mendoza MV, Milanés Guisado Y. Evaluación de la ciencia y los estudios bibliométricos. Sirvis área Educación (texto online). Hallado en: http:// www.unmsm.edu.pe/veterinaria/files/evaluacion_de_la_ciencia.pdf. Acceso en 01 marzo 2011.

4. Delgado-López-Cozar E, Ruiz-Pérez R, Jiménez-Contreras E. La Edición de Revistas Científicas: Directrices, Criterios y Modelos de Evaluación, Madrid: Fundación Española para la Ciencia y Tecnología (Fecyt), 2007. Hallado en: http:// recyt.fecyt.es/documentos/Fecyt.pdf. Acceso en 29 marzo 2011.

5. Román RA, Coord. La edición de revistas científicas guía de buenos usos, Madrid: Centro de Información y Documentación Científica CINDOC (CSIC), 2001. Hallado en: http://digital.csic.es/bitstream/10261/4347/1/R-21.pdf. Acceso en 29 marzo 2011.

6. Pulido M. El aporte de árbitros y editores al trabajo científico de los autores. Bol Oficina Sanit Panam 1990; 108: 57-61.

7. Campanario JM. El sistema de revisión por expertos (peer review): muchos problemas y pocas soluciones. Rev Esp Doc Cient. 2002; 25(3): 267-285. 